\title{
Assessment of patients' preferences regarding the characteristics associated with the treatment of chronic obstructive pulmonary disease
}

This article was published in the following Dove Press journal:

International Journal of COPD

16 April 2014

Number of times this article has been viewed

\section{Emel Bulcun \\ Mehmet Ekici \\ Aydanur Ekici}

Department of Pulmonary Medicine, Faculty of Medicine, University of Kırıkkale, Kırıkkale, Turkey
Correspondence: Emel Bulcun Department of Pulmonary Medicine, Faculty of Medicine, University of Kırıkkale, Kırıkkale 7I I00, Turkey

Tel +903182252485 ext 2188 $\mathrm{Fax}+903182240786$

Email emelbulcun@hotmail.com
Objective: Patient preferences regarding characteristics associated with the treatment of chronic obstructive pulmonary disease (COPD) must be determined to increase the compatibility between the patients and the treatments, but as yet no studies have been performed regarding these characteristics. Here, we evaluate the preferred characteristics associated with the treatment of patients with COPD.

Method: The expectations of patients receiving COPD therapy were assessed in six categories: time allocated by the physician to listen to patients' complaints, treatment to be applied, estimated adverse effect frequency concerning the therapy, ability of patients to visit the same physician each time, integral approach of the physician to the treatment of the patient, and therapy cost. These groups were divided into categories of therapy indicating 25 alternative treatment methods, using conjoint analysis. Patients were sorted to the 25 types of treatment with regard to their preferences.

Results: The major expectation of conjoint analysis associated with the treatment of COPD patients is for the therapy to allow the patients to completely recover from their complaints. The order preferred by patients of other treatment expectations is from sufficient time to be allowed by the physician to listen to the patient, to no cost for the treatment, to minimum adverse effects resulting from the treatment, to each follow-up to be performed by the same physician, and to the physician performing an assessment of the patient's well-being, rather than examining only the areas of complaint.

Conclusion: The major expectation of COPD patients regarding treatment was to completely recover with the help of the therapy. Considering the expectations of the patient may help improve the compatibility of the patient with the treatment.

Keywords: COPD, conjoint analysis, preferences of treatment

\section{Introduction}

Chronic obstructive pulmonary disease (COPD) is a generally recognized condition that results in poor clinical outcomes if not appropriately treated. Patients' preferences for medications to treat COPD may be important in determining their compatibility with the therapy, and thus, appropriate treatment approaches can reduce mortality rates.

In the health care field, there is substantial evidence suggesting that in addition to the outcome of the treatment, other aspects (eg, both the performance and the type of treatment process) are also important for the individuals. ${ }^{1,2}$

Conjoint analysis, which was originally developed for market research into customer preferences, is a method that allows us to investigate the relative data given by respondents concerning a set of attributes. ${ }^{3}$ It simulates the best way people make 
everyday choices when faced with multiple options and can help identify the characteristics of the treatments that guide patients' treatment preferences. ${ }^{4}$ This method can thus be used to analyze the preferences of patients regarding various treatment alternatives. In a recent study prepared by Osman et al, conjoint analysis was used to assess the relative importance of common symptoms in patients with asthma. ${ }^{5}$ However, conjoint analysis has not yet been used to examine patient preferences regarding the characteristics associated with treatment of patients with COPD.

Although treatment preference characteristics were not examined in patients with COPD, there are important studies regarding this issue in patients with asthma; for example, Ratcliffe et al examined treatment preference characteristics in patients with asthma by using conjoint analysis. ${ }^{6}$ In their study, Ratcliffe et al defined treatment preference characteristics as the different expectations of patients associated with treatment and clinical follow-up from doctors, such as the extent to which the doctor offers sufficient time to listen to the patient, the extent to which the patient sees the same doctor for every visit, the extent to which the doctor treats the patient as a whole person, and the extent to which treatment seems to relieve symptoms, adverse effects, and treatment cost. In our study, we used the same treatment preference characteristics used in the study. ${ }^{6}$

The main objective of our current study is to estimate the relative importance attached to the characteristics of the process and the outcomes of delivery of service during the treatment of COPD in patients who are currently receiving conventional and/or complementary treatment. In this study, using conjoint analysis, we examined the preferences of patients with COPD with regard to different aspects of pharmacologic treatment of the disease, including efficacy, adverse effects, and the costs and different expectations of patients that are associated with treatment and clinical followups performed by their doctors.

\section{Method}

\section{Subjects}

Consecutive patients diagnosed with COPD who were admitted to the policlinic at the Department of Chest Disease, Faculty of Medicine, Kırıkkale University, Kırıkkale, Turkey, were included in this study. The diagnosis of COPD conformed to Global initiative for chronic Obstructive Lung Disease (GOLD) guidelines. ${ }^{7}$ To be included in the study, patients had to be in stable condition without physical findings or symptoms regarding acute exacerbation or therapy modifications for 6 weeks before enrollment. In addition, they should have received optimal therapy according to the guidelines. Patients with the following criteria were excluded: severe congestive heart failure; other respiratory tract diseases such as asthma, interstitial lung disease, and obstructive sleep apnea; acute infection; and uncontrolled comorbidities such as malignancy, hepatic failure, and so on. A questionnaire regarding identity information, smoking history, medical history, and medications was filled out for each patient. Body mass index was calculated by measuring weight and height. Pulmonary function tests were performed with a flow-sensitive spirometer according to American Thoracic Society guidelines. ${ }^{8}$ The BODE (body mass index, airflow obstruction, dyspnea, and exercise capacity) index calculation was performed, with exercise capacity measured using the 6-minute walk distance test, according to the American Thoracic Society guidelines. ${ }^{9}$ Dyspnea was assessed using the Medical Research Council (MRC) dyspnea scale. ${ }^{10}$ The MRC scale was scored between 0 and 4 points according to the dyspnea intensity, with a low score indicating that the intensity of dyspnea is low. The multidimensional BODE index was calculated according to body mass index, forced expiratory volume in 1 second percentage, MRC dyspnea scale, and 6-minute walk distance. ${ }^{11}$ The BODE index is scored between 0 and 10 points. As the score increases, the intensity of the disease increases. COPD symptoms were determined with the COPD Associated Test (CAT). ${ }^{12}$ The total CAT score ranges between 0 and 40 . Higher scores indicate more symptoms associated with the disease. Written informed consent was obtained from all subjects before the study. The study was approved by the University of Kirıkkale, Faculty of Medicine ethics committee.

\section{Conjoint analysis}

In conjoint analysis, several characteristics of treatment are selected and a range of possible values (levels) is defined for each characteristic. This method of analysis has been used by Ratcliffe et $\mathrm{al}^{6}$ and by Johansson et al. ${ }^{13}$ These authors used this analysis to create a number of treatment concepts, each with different levels for the various characteristics. The selected characteristics were as follows: the extent to which treatment seems to relieve symptoms, the possibility of experiencing adverse effects resulting from treatment, the extent to which the doctor gives sufficient time to listen to the patient, the extent to which the patient sees the same doctor for his or her visit, the extent to which the doctor treats the patient as an entire person, and the costs of treatment.

The number of possible treatment concepts could be constructed from three attributes with three levels, two 
attributes with four levels, and one attribute with two levels (ie, $3^{3} \times 4^{2} \times 2=864$ ). The number of treatment concepts was reduced to 25. An SPSS package (Orthoplan; IBM Corporation, Armonk, NY, USA) was used to obtain the minimum number of scenarios needed to provide utility scores for each of the scenarios. The orthogonal design reduced the number of alternatives while minimizing the correlation between the remaining cards to allow the estimation of utilities in a statistically coherent way. The number of treatment concepts was reduced to 25 , using statistical analysis. Each of these 25 treatment scenarios was presented on a separate card. Twenty-five of the cards were used to calculate preferences. The patients were shown these treatment scenarios on the cards. The patients were instructed to rank the presented treatments according to their own opinions, considering aspects that were important to them in their COPD treatment. In these treatment scenarios, they were asked to score between 0 and 100 . If the same point is given on more than one card, the patients were asked to rerank these cards by preference. The patients' preferences were recorded on Orthoplan (range, 1-25).

The conjoint procedure requires two files, a data file and a plan file, as well as an indication of how the data were recorded (eg, each point is a preference score from 1 to 100). The plan file consists of the set of product profiles to be rated by the subjects and was generated using the "Generate Orthogonal Design" procedure in Orthoplan. The data file contains the preference scores or rankings of those profiles collected from the subjects. The plan and data files are specified with the plan and data subcommands, respectively. The method of data recording was specified with the sequence, rank, or score subcommands.

A measure of preference often used in conjoint analysis is "utility." The utility of a treatment concept is a function of the levels of the attributes in that concept. A higher level of utility expresses a greater preference for that treatment concept. For example, different patients are likely to favor the extent to which treatment seems to relieve symptoms differently. The utility measure not only expresses which alternative is the most preferred but also gives a measure of importance. A high relative level of utility indicates that the attribute was important to the patient and has had a large effect on the ranking of the treatments.

\section{Results}

\section{Demographic and clinic parameters of patients with COPD}

Forty-nine patients were included in the study. The characteristics of these patients are shown in Table 1. The study population comprised 46 men and three women. Using GOLD criteria, eight patients were classified as group A COPD patients, 34 patients were group B COPD patients, one patient was a group C COPD patient, and six patients were group D COPD patients.

The most preferred characteristic was on card 15, this card was the first choice for 21 patients. The least preferred characteristics were on cards 7 and 13. Card 7 was the last choice for eight patients, and card 13 was the last choice for eight patients (Table 2).

\section{Conjoint data}

Patients ranked a total of 25 treatments, which were used to estimate utility functions and express the patients' preferences for various characteristics. These cards were sequenced in the order of preference. Validation of this model was provided by calculating utility scores using each patient's utility function with regard to the 25 treatments. Calculated scores were then put in order by rank. Original rankings were compared pairwise with theoretical rankings resulting from calculated utility scores.

The average relative importance of the characteristics, based on individual preferences, is presented in Table 3, which lists the most preferred treatments. The extent to which treatment seems to relieve symptoms was the most important patient preference (difference between highest and lowest utility levels, 53.4). Patients ranked other preferences regarding their treatment as follows: extent to which the doctor gives sufficient time to listen to the patient (difference, 14.4), possibility of experiencing adverse effects from treat-

Table I Demographic and clinical parameters of patients with chronic obstructive pulmonary disease

\begin{tabular}{ll}
\hline Variable & $\begin{array}{l}\text { Patients with COPD, } \\
\text { mean } \pm \text { SD (N=49) }\end{array}$ \\
\hline Age & $60.8 \pm 8.6$ \\
Sex male/female & $46 / 3$ \\
Body mass index & $26.9 \pm 5.0$ \\
Smoking packs/year & $33.4 \pm 12.9$ \\
FEV\% & $54.3 \pm 22.2$ \\
FVC\% & $61.2 \pm 22.0$ \\
FEV/FVC\% & $64.3 \pm 15.0$ \\
Peak expiratory flow, \% & $54.8 \pm 22.4$ \\
Mid-expiratory flow rate, \% & $36.2 \pm 21.4$ \\
Body mass index, obstruction, dyspnea, & $3.3 \pm 2.4$ \\
and exercise capacity index & \\
Medical Research Council score ${ }^{10}$ & $2.3 \pm 1.2$ \\
Chronic Obstructive Pulmonary & $19.8 \pm 9.3$ \\
Disease Associated Test ${ }^{12}$ & \\
\hline Abrevitions: COPD, &
\end{tabular}

Abbreviations: COPD, chronic obstructive pulmonary disease; SD, standard deviation; $\mathrm{FEV}_{1}$, forced expiratory volume in I second; FVC, forced vital capacity. 


\section{Table 2 Card characteristics}

\section{Card characteristics and preference}

The most preferred (from most preferred to least preferred): card $15(\mathrm{~N}=2 \mathrm{I} ; 42.9 \%)$

Extent to which the doctor gives sufficient time to listen to the patient: The doctor always gives sufficient time to listen (2)

Extent to which treatment seems to relieve symptoms:

Treatment seems to completely relieve symptoms (3)

Possibility of experiencing adverse effects from treatment: Possibility of experiencing adverse effects from treatment was $I$ in $25=4 \%$ (2)

Extent to which the patient sees the same doctor for each of her/ his visits: The patient always sees the same doctor for each of her/his visits (2)

Extent to which the doctor treats the patient as an entire person: The doctor treats the patient regarding only his/her symptoms (0) Costs of treatment: The cost of treatment was 20 TL (I0 USD) (2)

The least preferred (from least preferred to most preferred): card 7

$(\mathrm{N}=8 ; 16.3 \%)$

Extent to which the doctor gives sufficient time to listen to the patient: The doctor rarely gives sufficient time to listen (0)

Extent to which treatment seems to relieve symptoms:

Treatment rarely seems to relieve symptoms $(0)$

Possibility of experiencing adverse effects from treatment: Possibility of experiencing adverse effects from treatment was 1 in $10=10 \%$ (I) Extent to which the patient sees the same doctor for each of her/ his visits: The patient always sees the same doctor for each of his/her visits (2)

Extent to which the doctor treats the patient as an entire person: The doctor treats the patient regarding only his/her symptoms (0)

Costs of treatment: The cost of treatment was 60 TL (30 USD) (0)

The least preferred (from least preferred to most preferred): card 13 $(\mathrm{N}=8 ; 16.3 \%)$

Extent to which the doctor gives sufficient time to listen to the patient: The doctor rarely gives sufficient time to listen $(0)$

Extent to which treatment seems to relieve symptoms:

Treatment rarely seems to relieve symptoms (0)

Possibility of experiencing adverse effects from treatment: Possibility

of experiencing adverse effects from treatment was I in $5=20 \%$ (0)

Extent to which the patient sees the same doctor for each of her/

his visits: The patient always sees the same doctor for each of her/his visits (2)

Extent to which the doctor treats the patient as an entire person:

Extent to which the doctor treats the patient as an entire person (I)

Costs of treatment: The cost of treatment was 40 TL (20 USD) (I)

Abbreviations: TL, Turkish Lira; USD, US dollars.

ment (8.2), costs of treatment (13.2), extent to which the patient sees the same doctor for each of his/her visits (6.0), and extent to which the doctor treats the patient as an entire person (4.5). The utility scores indicate the level of patients' preferences. Higher utility values indicate higher levels of preference. Each treatment concept was ranked according to the levels of preference.

"Always" was the option most often chosen for "extent to which the doctor gives sufficient time to listen to the patient", followed by "sometimes", and "rarely." For "extent to which treatment seems to relieve symptoms," the most preferred option was "completely", followed by "mostly", "partially", and "rarely". For "possibility of experiencing adverse effects from treatment" the most preferred concept was 1 in $25(4 \%)$ frequency, followed by frequencies of 1 in $10(10 \%)$, and 1 in 5 (20\%). For "extent to which the patient sees the same doctor for each of his/her visits" the most preferred concept was "always", followed by "sometimes", and "never." For "extent to which the doctor treats the patient as an entire person" the most preferred concept was "does", as opposed to "does not". Finally, with regard to "costs of treatment" the most preferred concept was "no cost" followed by "20 TL (Turkish Lira) (10USD)", "40 TL (20USD)", and "60 TL (30USD)."

\section{Discussion}

The findings from this study are compatible with those of other studies that have used conjoint analysis to establish patient preferences in other areas of treatment. ${ }^{14,15}$ This study has investigated patients' preferences associated with their COPD treatment. The most striking result of this study is that the most important expectation of patients with COPD is to recover from their complaints. In addition, the utility values increased with the increasing degree of recovering symptoms.

The most desired expectation patients have for their treatment is relief from the symptoms of the disease. This result is not surprising because patients with COPD often have symptoms that may disrupt their quality of life. This study included few patients with forced expiratory volume in 1 second $\left(\mathrm{FEV}_{1}\right)>80 \%$ and $\mathrm{FEV}_{1}$ /forced vital capacity $<70 \%$. However, the levels of CAT scores and MRC scores were higher among all patients. Higher CAT and MRC scores indicate that the patients had severe symptoms resulting from their disease. Therefore, these patients' most important expectations may be recovery from their symptoms. The findings from this study are consistent with those of other studies that have used conjoint analysis to establish patient treatment preferences. ${ }^{6,13}$ Similarly to our results these studies showed that one of the most important expectations of patients with asthma regarding their treatment was the improvement of their symptoms.

The second most important treatment characteristic according to the patients was sufficient time allocated by their doctor for listening to them. The other expectations of patients are being seen by the same doctor in every visit and being treated as an entire person by their doctor. Similarly, the study of Ratcliffe et $\mathrm{al}^{6}$ indicated that almost all of the respondents thought that it is very important that the doctor should listen and discuss the treatment options 
Table 3 Utilities from a single hypothetical patient based on the average of the sample population of the study

\begin{tabular}{|c|c|c|c|c|c|}
\hline Preference and utility value & I & 2 & 3 & 4 & $\begin{array}{l}\text { Difference between } \\
\text { highest and lowest } \\
\text { utility levels }\end{array}$ \\
\hline $\begin{array}{l}\text { Extent to which the doctor gives } \\
\text { sufficient time to listen to the patient }\end{array}$ & Rarely & Sometimes & Always & - & \\
\hline Utility value & -1.5 & -0.5 & 2.0 & - & 14.4 \\
\hline $\begin{array}{l}\text { Extent to which treatment seems } \\
\text { to relieve symptoms }\end{array}$ & Rarely & Partially & Mostly & Completely & \\
\hline Utility value & -6.3 & -3.2 & 2.8 & 6.7 & 53.4 \\
\hline $\begin{array}{l}\text { Possibility of experiencing adverse } \\
\text { effects from treatment }\end{array}$ & I in $5=20 \%$ & 1 in $10=10 \%$ & I in $25=4 \%$ & - & \\
\hline Utility value & -0.9 & -0.06 & 1.0 & - & 8.2 \\
\hline $\begin{array}{l}\text { Extent to which the patient sees the } \\
\text { same doctor for each of his/her visits }\end{array}$ & Never & Sometimes & Always & - & \\
\hline Utility value & -0.8 & 0.2 & 0.5 & - & 6.0 \\
\hline $\begin{array}{l}\text { Extent to which the doctor treats } \\
\text { the patient as an entire person }\end{array}$ & Does not & Does & & - & \\
\hline Utility value & -0.5 & 0.5 & & - & 4.5 \\
\hline Costs of treatment & 60 TL (30 USD) & 40 TL (20 USD) & $20 \mathrm{TL}$ ( 10 USD) & No cost & \\
\hline Utility value & -1.8 & -0.06 & 0.5 & $\mathrm{I} .4$ & 13.2 \\
\hline
\end{tabular}

Abbreviations: TL, Turkish Lira; USD, US dollars.

with the patient. In addition, most of the respondents from hospital samples felt it is very important for the doctor to treat the patient as an entire person. The time allocated by the doctor to listen to the patient is the important preference characteristic for them. The doctors may sufficiently deal with and may treat the patient as an entire person when they spend sufficient time with the patients. Therefore, patients prefer the same doctor for their treatments because they think doctors who spend enough time with their patients may be helpful. These patient preferences are in parallel with the results of other studies that show a positive correlation between good doctor/patient communication and compatibility. ${ }^{16}$ It is common for patients with COPD to neglect their treatment or to refuse treatment because of not their doctors not meeting their expectations. Having doctors allocate sufficient time for their patients may improve the treatment compatibility of patients and help them use drug treatment more efficiently.

In this study, it also has been shown that patients prefer treatments with the fewest adverse effects, which is not surprising. Adverse effects resulting from their treatment can be seen in patients with COPD, but this problem is not of primary importance in terms of patient treatment preferences.

According to the study, one other important expectation of patients regarding their treatments was low treatment cost. The importance of treatment cost for patients may vary according to the economic conditions found in every country. Poor social and economic status can facilitate tobacco smoking, ${ }^{17}$ and lower socioeconomic status may be seen more frequently in patients with COPD. Therefore, patients with COPD can be expected to prefer lower costs for their treatment because of common lower socioeconomic status among patients with COPD.

The current study has some limitations. The first is the limited number of COPD patients sampled. However, in our study, significant and important parameters and utility values with a wide range were observed. Second, this study included very few women with COPD when compared with male patients with COPD. In our country, diagnosis of COPD in the male population is more frequent than in the female population, and a history of smoking among women is less obvious than in men. The ratio of men and women with COPD in our study parallels the gender distribution of patients with COPD in our country.

\section{Conclusion}

This study describes the application of the conjoint analysis technique to the measurement of patient preferences regarding the characteristics of COPD. The most important expectation patients with COPD had of their treatments was recovery from their complaints. In patients with COPD, treatments focused on saving patients from their symptoms improve treatment compatibility. Moreover, having doctors allocate sufficient time to listen their patients will help the patients to be under control regularly and not to neglect their treatment. Taking the expectations of patients with COPD into consideration may help improve the compatibility of their treatment. 


\section{Disclosure}

The authors report no conflicts of interest in this work.

\section{References}

1. Edworthy SM, Devins GM. Improving medication adherence through patient education distinguishing between appropriate and inappropriate utilization. Patient Education Study Group. J Rheumatol. 1999;26(8): 1793-1801.

2. Daltroy LH. Doctor-patient communication in rheumatological disorders. Baillieres Clin Rheumatol. 1993;7(2):221-239.

3. Ryan M, McIntosh E, Shackley P. Methodological issues in the application of conjoint analysis in health care. Health Econ. 1998;7(4):373-378.

4. Sweileh WM, Ihbesheh MS, Jarar IS, et al. Self-reported medication adherence and treatment satisfaction in patients with epilepsy. Epilepsy Behav. 2011;21(3):301-305.

5. Osman LM, McKenzie L, Cairns J, et al. Patient weighting of importance of asthma symptoms. Thorax. 2001;56(2):138-142.

6. Ratcliffe J, Van Haselen R, Buxton M, Hardy K, Colehan J, Partridge M. Assessing patients' preferences for characteristics associated with homeopathic and conventional treatment of asthma: a conjoint analysis study. Thorax. 2002;57(6):503-508.

7. Global Initiative for Chronic Obstructive Lung Disease [homepage on the Internet]. 2011. Available from: http://www.goldcopd.org/ Guidelines/guideline-2011-gold-report.html. Accessed March 25, 2013.

8. Standardization of spirometry - 1987 update. Statement of the American Thoracic Society. Am Rev Respir Dis. 1987;136(5):1285-1298.
9. ATS Committee on Proficiency Standards for Clinical Pulmonary Function Laboratories. ATS statement: guidelines for the six-minute walk test. Am J Respir Crit Care Med. 2002;166(1):111-117.

10. Bestall JC, Paul EA, Garrod R, Garnham R, Jones PW, Wedzicha JA. Usefulness of the Medical Research Council (MRC) dyspnoea scale as a measure of disability in patients with chronic obstructive pulmonary disease. Thorax. 1999;54(7):581-586.

11. Celli BR, Cote CG, Marin JM, et al. The body-mass index, airflow obstruction, dyspnea, and exercise capacity index in chronic obstructive pulmonary disease. $N$ Engl J Med. 2004;350(10):1005-1012.

12. Ardelean DL, Iulia L, Popescu R, et al. Evaluation of COPD patients using CAT-COPD assessment test. Pneumologia. 2012;61(4):221-229.

13. Johansson G, Ställberg B, Tornling G, et al. Asthma treatment preference study: a conjoint analysis of preferred drug treatments. Chest. 2004;125(3):916-923.

14. Bryan S, Buxton M, Sheldon R, Grant A. Magnetic resonance imaging for the investigation of knee injuries: an investigation of preferences. Health Econ. 1998;7(7):595-603.

15. Ryan M. Using conjoint analysis to take account of patient preferences and go beyond health outcomes: an application to in vitro fertilisation. Soc Sci Med. 1999;48(4):535-546.

16. Korsch BM, Negrete VF. Doctor-patient communication. Sci Am. 1972;227(2):66-74.

17. Cakmak G, Saglam ZA, Saler T, Yenigun M, Temiz LU. Socio-economic status of smokers presenting to the outpatient service: does chronic obstructive pulmonary disease make a difference? Indian J Chest Dis Allied Sci. 2012;54(1):19-22.

\section{Publish your work in this journal}

The International Journal of COPD is an international, peer-reviewed journal of therapeutics and pharmacology focusing on concise rapid reporting of clinical studies and reviews in COPD. Special focus is given to the pathophysiological processes underlying the disease, intervention programs, patient focused education, and self management protocols.

\section{Dovepress}

This journal is indexed on PubMed Central, MedLine and CAS. The manuscript management system is completely online and includes a very quick and fair peer-review system, which is all easy to use. Visit http://www.dovepress.com/testimonials.php to read real quotes from published authors. 